\title{
In vitro Mass Multiplication with Pure Genetic Identity
} in Anthurium andreanum Lind.

\author{
S. Gantait, N. Mandal, S. Bhattacharyya ${ }^{1}$ and P. K. Das ${ }^{1}$ \\ Department of Biotechnology, Instrumentation and Environmental Science, \\ B.C.K.V., Mohanpur, W.B.-741252, India
}

Key words: Anthurium, In vitro cloning, Multiple shoot, Genetic identity

\begin{abstract}
A novel protocol for enhanced in vitro multiple shoot induction was developed for Anthurium andreanum Lind. First shoot bud was induced within a week in MS supplemented with $0.1 \mathrm{mg} / \mathrm{l} \mathrm{NAA}$ and $0.25 \mathrm{mg} / \mathrm{l} \mathrm{BAP}$ where maximum six buds from single apical bud explant appeared within next 20 days. For multiple shoot proliferation MS with $0.5 \mathrm{mg} / \mathrm{l} \mathrm{BAP}$ and $60 \mathrm{mg} / \mathrm{l}$ adenine sulphate (ADS) proved to be best resulting ten multiple shoots per inoculated shoot bud within 50 days. As many as 11 roots per plantlet were produced in 27 days using MS with 0.5 $\mathrm{mg} / \mathrm{l}$ IAA and $2 \mathrm{~g} / \mathrm{l}$ activated charcoal. Autoclaved sand and intermittent water spraying optimized the primary hardening period of 15 days and then earthen pots filled with sand, soil, charcoal and coconut fibre ensured the recovery of 51 well hardened plantlets out of 60 in next 30 days showing $85 \%$ success. The genetic identity of both ex vitro hardened clones and in vitro sustained clones with their mother plant were tested using 10 ISSR primers, displayed no polymorphism.
\end{abstract}

\section{Introduction}

Anthurium andreanum Lind. of Araceae, a perennial, herbaceous plant, native to tropics of Central and South America is highly valued for its colourful attractive luxurious flowers and exotic foliage. Among the known about 1500 tropical ornamental Anthurium species, Anthurium andreanum is commercially exploited extensively as cut flower and potted plant throughout the world primarily because of its long vase-life. It is propagated both by seeds (Dufour and Guerin 2003) and by vegetative means (cuttings and suckers). Seed contamination and germination often impose problem and to record high level of germination $A$. andreanum seeds require continuous light condition which is hardly available under prevailing natural field condition. Conventional vegetative propagation

1Department of Genetics, B.C.K.V., Mohanpur, W.B.-741252, India. 
proves to be time consuming and takes years to develop commercial quantities of elite clones (Martin et al. 2003). Tissue culture techniques appear as an attractive alternative to increase the production (Chen et al. 1997). Plant regeneration of A. andreanum has been achieved directly from lamina explants (Martin et al. 2003) or from root explant (Chen et al. 1997) as well as from axillary bud (Kunisaki 1980, Mahanta and Paswan 2001). The present study aims to generate in vitro directly from apical shoot bud of $A$. andreanum cv. CanCan for commercial application. The study concerned with the following objectives: (i) to develop a novel protocol of in vitro cloning as well as establishment of cost effective process for ex vitro acclimatization, (ii) to enhance the multiplication rate through induction of multiple shoots, (iii) to raise and maintain sustainable pool of propagules for further multiplication and constant supply and (iv) finally to ensure the genetic identity of the sustainable quality propagules through DNA fingerprinting.

\section{Materials and Methods}

Apical shoot buds of $2 \mathrm{~cm}$ were collected from 30 days old young plants (Anthurium andreanum Lind.) generated through suckers and surface sterilized with Teepol, washed with sterile water, treated with antifungal solution Cetrimide for five minutes. Then treated with $\mathrm{NaOCl}$ for five minutes, washed and treated again with $0.1 \%(\mathrm{w} / \mathrm{v}) \mathrm{HgCl}_{2}$ for five min. The explants were then thoroughly washed four - five times in sterile double distilled water. Explants were trimmed to $1 \mathrm{~cm}$. The whole process was performed under strict aseptic condition.

To induce bud breaks the explants were inoculated in MS basal medium, plus 3\% (w/v) sucrose supplemented with varying levels of NAA and BAP (Table 1). The induced buds were cultured on MS with different concentrations of BAP and NAA with ADS for multiple shoot proliferation (Table 2). During multiple shoot proliferation subculturing was done once after 30 days. For root induction and elongation MS basal medium was supplemented with different concentrations of IAA and BAP as well as activated charcoal (AC) (Table 3). The entire activity was performed under the laminar flow and the modified MS solidified with $0.7 \%(\mathrm{w} / \mathrm{v})$ agar and $\mathrm{pH}$ was adjusted to 5.7 before autoclaving at $1.06 \mathrm{~kg} / \mathrm{cm}^{2}$ and $121^{\circ} \mathrm{C}$ for $15 \mathrm{~min}$. During shoot bud break, multiple shoot proliferation and root induction the light intensity was 3000 lux with $25 \pm 2^{\circ} \mathrm{C}$ and $60 \% \mathrm{RH}$.

Rooted plantlets were subjected to two step hardening process. First rooted microplantlets were transferred to small earthen pots containing autoclaved sand and sprayed water intermittently to maintain mist condition. The plantlets were allowed to grow for 15 days. The semi-hardened plantlets with five - six primary 
leaves were transferred to large pots having sand, soil, charcoal and coconut fibre mixture $(1: 1: 1: 1)$ and water sprayed intermittently to ensure high level of humidity. The entire hardening was done under the shade. Well hardened plants were then recovered.

To test the genetic identity (purity) the regenerated plants were subjected to DNA fingerprinting using 10 ISSR primers (Table 4) where DNA extraction was done following Bhattacharyya and Mandal (1999).

To maintain the pool of propagules proliferated multiple shoots were cultured on MS supplemented with identified concentrations of BAP and ADS followed by three subcultures at one month interval over a period of three months so that they can be used for further root induction and hardening. This would facilitate the steady supply of propagules as and when necessary. The clonal fidelity of shootlets cultured for such a long period was assessed through ISSR markers as described earlier.

\section{Results and Discussion}

In vitro direct organogenesis from different explant sources had been successfully achieved in several ornamental plants including begonia, chrysanthemum, rose, cyclamen (Rout et al. 2006). In Anthurium also similar attempt was successfully made to facilitate in vitro mass propagation (Mahanta and Paswan 2001). Here in vitro micropropagation is reported directly from apical bud through modified MS with specific formulations.

The surface sterilized apical shoot buds were cultured on MS supplemented with different concentrations of NAA and BAP. The earliest bud induction was found on sixth day following inoculation and out of 20 explants after three repeated experiments on an average around 18 recorded bud breaks when MS was supplemented with $0.1 \mathrm{mg} / \mathrm{l} \mathrm{NAA}$ and $0.25 \mathrm{mg} / \mathrm{l} \mathrm{BAP}$. Following 26 days of prolonged culture in this medium maximum number of six greenish shoot buds appeared though on an average it was around four (Table 1, Fig. 1a). In this case, however very low concentrations of NAA and BAP triggered the bud break for apical shoot bud while BAP, IAA, PVP with coconut water (CW) in MS induced bud breaks in axillary shoot explant in A. andreanum (Mahanta and Paswan 2001). It seems that very low concentrations of BAP and NAA proved to be effective for establishment of apical shoot buds and prolonged culture of 26 days in the presence of these growth regulators helped further bud establishment and promotion of dark green bud colour. Thus the establishment of modified MS with a suitable amount of cytokinin and auxin played positive role in initiation and establishment of apical shoot. 
For multiple shoot proliferation MS basal medium was modified with as many as ten combinations of NAA and BAP with the addition of ADS. It was observed that on an average 19.33 buds out of 20 individuals started responding within ten days of culture on MS with $0.5 \mathrm{mg} / \mathrm{l} \mathrm{BAP}$ and $60 \mathrm{mg} / \mathrm{l}$ ADS meaning that almost $100 \%$ buds recorded shoot proliferation (Table 2 ). This demonstrates that BAP alone in presence of ADS successfully induced multiple shoots. There are several reports for the use of BAP alone in inducing multiple shoots in many crops (Bhojwani 1981). What is significant here is that the addition of ADS might have played a very important role in shoot proliferation positively. The similar

Table 1. Apical bud explants response to different growth regulators in MS medium.

\begin{tabular}{cccccl}
\hline \multicolumn{2}{c}{$\begin{array}{c}\text { Growth } \\
\text { regulators } \\
(\mathrm{mg} / \mathrm{l})\end{array}$} & $\begin{array}{c}\text { No. of } \\
\text { responding } \\
\text { inoculants } \\
\text { out of } 20\end{array}$ & $\begin{array}{c}\text { Days to first } \\
\text { bud } \\
\text { induction }\end{array}$ & $\begin{array}{c}\text { No. of shoot } \\
\text { bud/ explant }\end{array}$ & Remarks \\
\cline { 1 - 5 } NAA & BAP & & & \\
\cline { 1 - 5 } 0.0 & 0.0 & $0.33 \pm 0.57^{\mathrm{e}}$ & $32.0 \pm 18.47^{\mathrm{a}}$ & $0.67 \pm 1.15^{\mathrm{e}}$ & Maximum 18 \\
0.1 & 0.1 & $3.67 \pm 1.15^{\mathrm{d}}$ & $14.67 \pm 1.15^{\mathrm{e}}$ & $2.00 \pm 0.00^{\mathrm{cd}}$ & inoculants responded \\
0.1 & 0.25 & $17.33 \pm 0.57^{\mathrm{a}}$ & $6.67 \pm 0.57 \mathrm{~g}$ & $4.33 \pm 1.52^{\mathrm{a}}$ & \\
0.1 & 0.5 & $12.67 \pm 0.57^{\mathrm{b}}$ & $9.33 \pm 0.57^{\mathrm{f}}$ & $3.67 \pm 0.57^{\mathrm{ab}}$ & Earliest bud induction \\
0.1 & 1.0 & $10.00 \pm 1.73^{\mathrm{c}}$ & $10.0 \pm 1.00^{\mathrm{f}}$ & $3.33 \pm 0.57^{\mathrm{ab}}$ & on sixth day \\
0.5 & 0.1 & $3.33 \pm 0.57^{\mathrm{d}}$ & $20.33 \pm 2.08^{\mathrm{b}}$ & $1.33 \pm 0.57^{\mathrm{de}}$ & Maximum six shoot \\
0.5 & 0.25 & $3.67 \pm 1.15^{\mathrm{d}}$ & $17.67 \pm 0.57^{\mathrm{c}}$ & $2.00 \pm 0.00^{\mathrm{cd}}$ & buds induced on 26th \\
0.5 & 0.5 & $3.33 \pm 0.57^{\mathrm{d}}$ & $15.67 \pm 0.57^{\mathrm{de}}$ & $2.67 \pm 0.57^{\mathrm{bc}}$ & day \\
0.5 & 1.0 & $11.33 \pm 1.15^{\mathrm{bc}}$ & $16.67 \pm 1.52^{\mathrm{cd}}$ & $3.00 \pm 0.00^{\mathrm{bc}}$ & \\
Overall mean & 7.29 & 15.89 & 2.56 & \\
SE & & 0.5996 & 0.6199 & 0.4082 & \\
\hline
\end{tabular}

Data represent mean \pm SD of 20 replicants per treatment in three repeated experiments. Different letters indicate significant difference at $\mathrm{p}<0.05$ (DMRT).

effect of addition of the ADS to the regeneration medium for increased shoot multiplication has also been reported in Pentanema indicum (Sivanesan and Jeong 2007). Under this modified MS on an average ten shoots per plantlet were recorded on 50th day of culture (Fig. 1b) and average shoot length was around 8 $\mathrm{cm}$. Shoots were healthy, stout and green in appearance. The modified MS with $0.5 \mathrm{mg} / \mathrm{l} \mathrm{BAP}$ and $60 \mathrm{mg} / \mathrm{l}$ ADS thus proved to be most effective formulation for multiple shoot proliferation and shoot growth than any other tried combinations confirmed by DMRT.

Sixty shootlets were transferred to MS fortified with varying concentrations of IAA, BAP and AC to induce roots. MS with $0.5 \mathrm{mg} / \mathrm{l}$ IAA and $2 \mathrm{~g} / \mathrm{l}$ AC induced root as early as ten days of culture where almost $100 \%$ shootlets produced root (19.67 out of 20 shootlets) (Fig. 1c). On 27th day of culturing average number of roots per shootlet was 9.67 and average root length was more than $10 \mathrm{~cm}$. These roots were robust and healthy (Table 3, Fig. 1d). It is to be mentioned here that 
the low concentration of IAA alone in presence of AC proved to be very efficient in inducing as well as promoting root growth. However, the addition of AC seems to provide additional beneficial advantage. It is reported that AC eliminate light and provides a reasonable physical environment for the rhizosphere and helps rooting (Nissen and Sutter 1990). It is further noted that on 27th day of culture out of 60 shootlets 55 maintained robust healthy root and they were advanced for acclimatization.
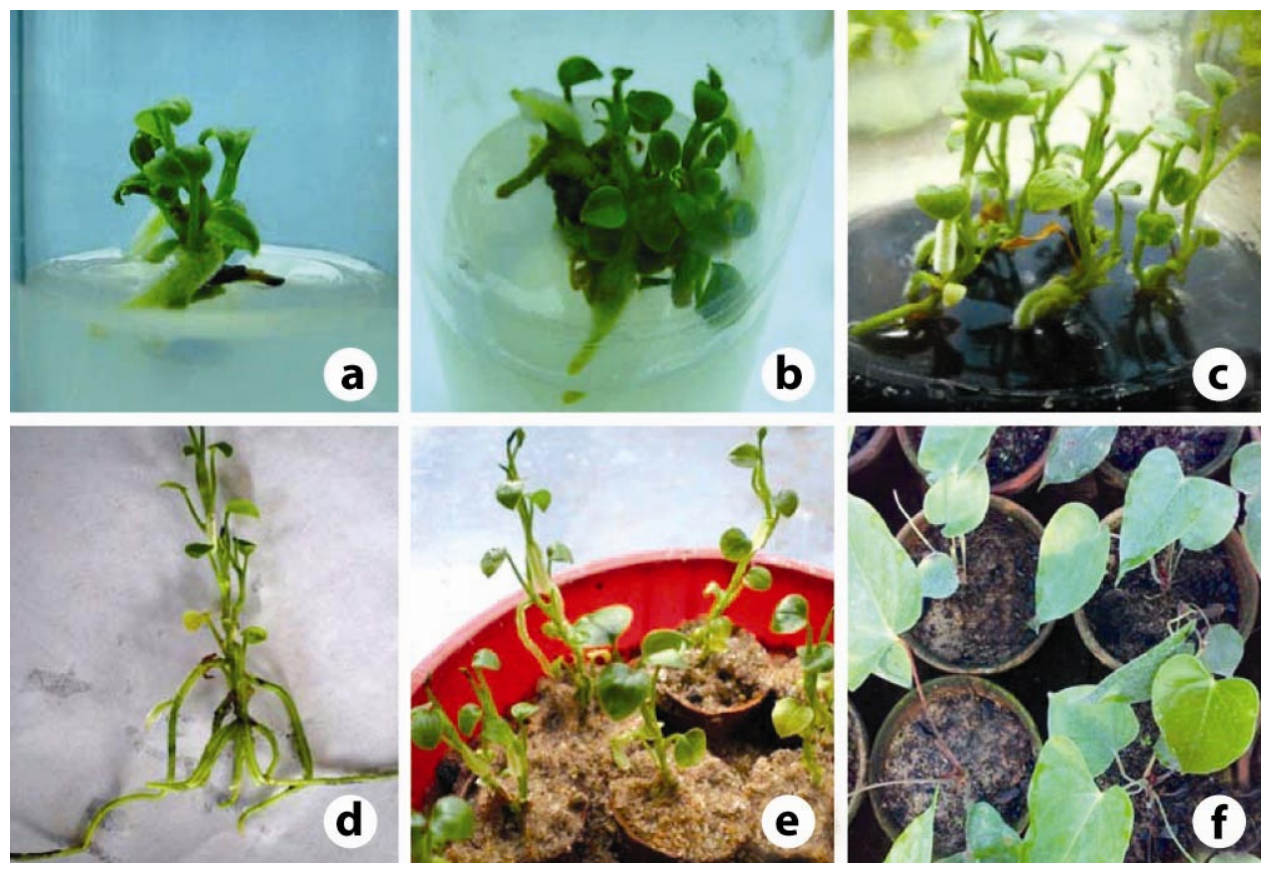

Fig. 1. (a) Breaking of apical bud. (b) Multiple shoot proliferation. (c) Rooting of microshoots. (d) Plantlet with robust healthy roots. (e) Primary hardening on autoclaved sand. (f) Final hardening on sand, soil, charcoal and coconut fibre mixture.

Development of a good number of stout roots on each shootlet is necessary for better acclimatization. Hence, after profusely robust rooting 55 plantlets were first transferred to small earthen pots (each pot with single plantlet) containing autoclaved sand (Fig. 1e) with intermittent water spraying to maintain moist condition under shade. After 15 days of hardening when five - six primary leaves appeared these plantlets were transferred to larger earthen pots containing sand, soil, charcoal and coconut fibre mixture (1:1:1:1) (Fig. 1f). Intermittent water supply was maintained and sufficient shade was provided. After 30 days of growth 51 well hardened plants were recovered. Thus in the final analysis out of 60 regenerated shootlets from the single apical bud 51 acclimatized healthy growing plants were ready for field transfer. Following the above mentioned protocol and two step hardening $85 \%$ success was ensured. 


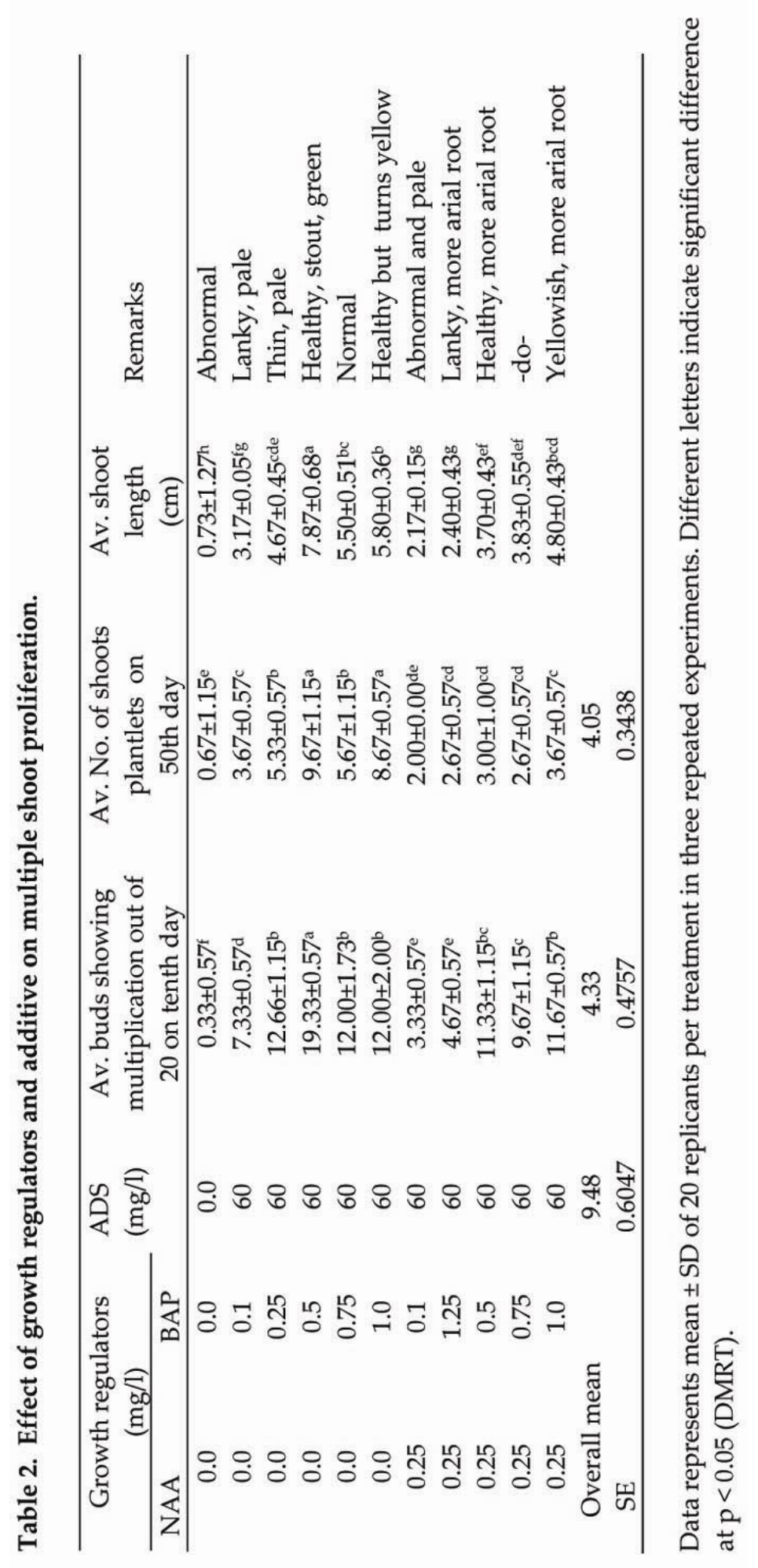




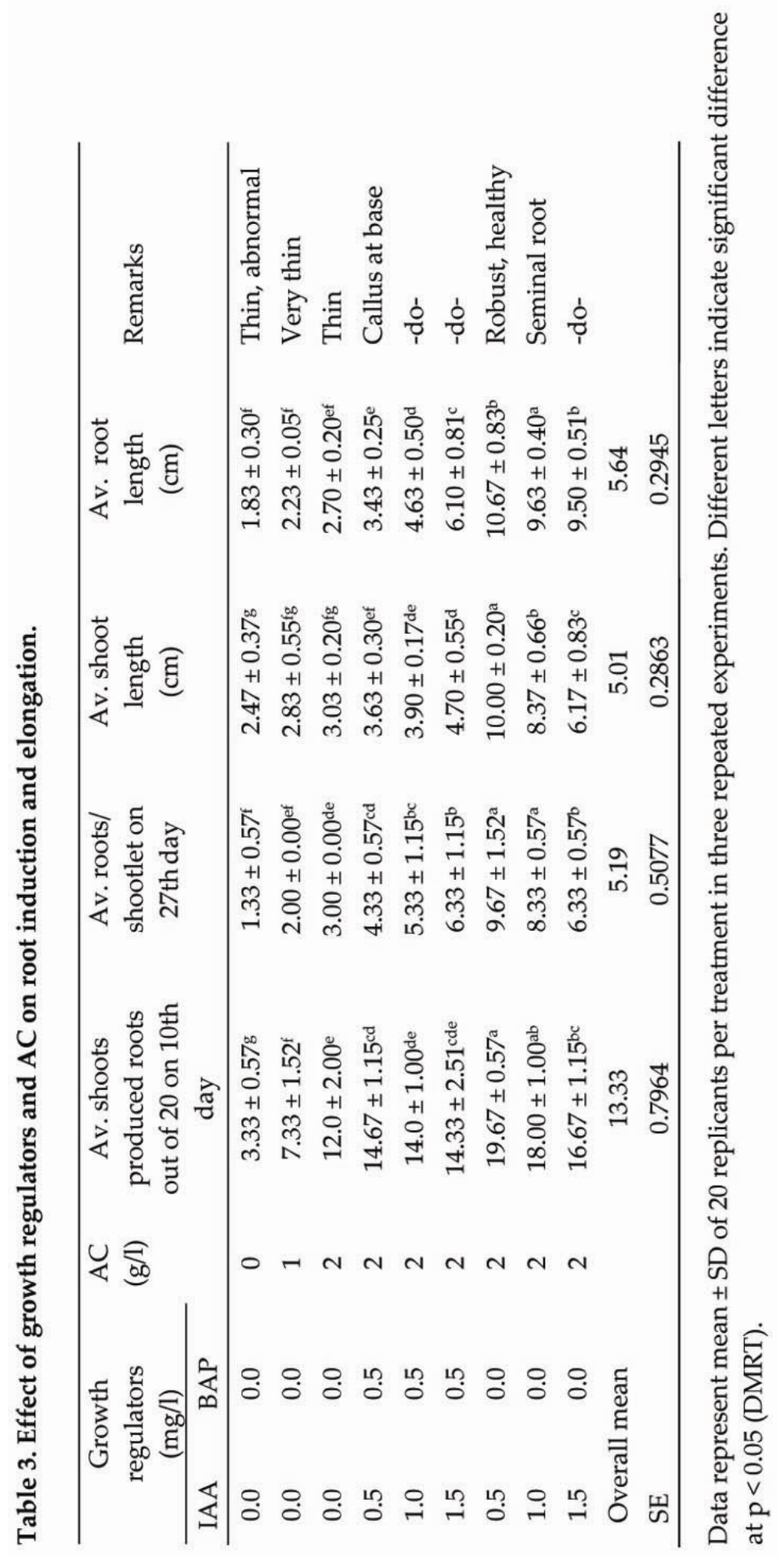


Table 4. ISSR primers used for the test of clonal fidelity.

\begin{tabular}{cl}
\hline Oligo-name & Sequences \\
\hline IS-6 & 5' GAG AGA GAG AGA GAG AC3' \\
IS-7 & 5' ' GTG TGT GTG TGT GTG TA 3' \\
IS-8 & 5' ' AGA GAG AGA GAG AGA GC3' \\
IS-9 & 5' TGT GTG TGT GTG TGT A3' \\
IS-10 & 5' CGA GAG AGA GAG AGA GA3' \\
IS-11 & 5' CAC ACA CAC ACA CAC AG 3' \\
IS-12 & 5' GTG TGT GTG TGT GTG TC3' \\
IS-61 & 5' GA GA GA GA GA GA GA GA T3' \\
IS-63 & 5' AG AG AG AG AG AG AG AG C3' \\
IS-65 & 5' AG AG AG AG AG AG AG AG T3' \\
\hline
\end{tabular}

Table 5. Flow diagram illustrating entire activity of in vitro cloning.

\begin{tabular}{|c|c|c|}
\hline $\begin{array}{l}\text { Days to each } \\
\text { stage }\end{array}$ & $\begin{array}{c}\text { Major steps taken during micropropagation along with } \\
\text { successful results }\end{array}$ & $\begin{array}{l}\text { Days after } \\
\text { inoculation }\end{array}$ \\
\hline \multicolumn{3}{|c|}{ Apical shoot bud $(2 \mathrm{~cm})$ explant from 30 days old young plant } \\
\hline \multicolumn{3}{|c|}{ Surface sterilization } \\
\hline \multicolumn{3}{|c|}{ Inoculation in shoot bud induction media } \\
\hline & Earliest bud induced on MS $+0.1 \mathrm{mg} / 1 \mathrm{NAA}+0.25 \mathrm{mg} / \mathrm{l} \mathrm{BAP}$ & \\
\hline \multirow{2}{*}{20} & Max. of 6 buds induced & 26 \\
\hline & Seperated buds on multiple shoot proliferation media & \\
\hline \multirow[t]{2}{*}{50} & 10 shoots/microplant on MS + $0.5 \mathrm{mg} / \mathrm{l} \mathrm{BAP}+60 \mathrm{mg} / \mathrm{l}$ ADS & 76 \\
\hline & 60 single-shooted micriplants cultured on root induction \& & \multirow[t]{2}{*}{103} \\
\hline \multirow[t]{2}{*}{27} & 10 roots/ microplant with max. $11 \mathrm{~cm}$ length on & \\
\hline & $\mathrm{MS}+0.5 \mathrm{mg} / \mathrm{l} \mathrm{IAA}+2 \mathrm{~g} / \mathrm{l} \mathrm{AC}$ & \multirow[t]{2}{*}{118} \\
\hline \multirow{3}{*}{30} & 55 robust rooted microplantlet transferred to pots having & \\
\hline & autoclaved sand \& water spraying & \multirow[t]{2}{*}{148} \\
\hline & $\begin{array}{l}\text { Semi-hardened 5-6 leaved plantlets transferred to large earthen } \\
\text { pots having sand:soil:charcoal:coconut fibre }(1: 1: 1: 1) \text { with } \\
\text { intermittent water spraying ensured } 51 \text { hardened plants }\end{array}$ & \\
\hline
\end{tabular}

To illustrate the entire activity followed a flow-diagram is presented (Table 5). It is clear from the activity chart that from initial bud breaks to complete 
hardening of plantlets it would take around 148 days or almost five months to raise as many as 51 well hardened plants from a single apical shoot bud.

An attempt was made to maintain regenerated shootlets under culture in prescribed modified MS. To maintain steady supply of propagules to be undergone the process of rooting and hardening as described earlier. It was with two distinct advantages. First, there was no need to start afresh from the apical shoot bud inoculation. As a result time lag would be curtailed by at least four weeks. Finally, unbroken propagule supply can possibly be sustained over a period of time provided no genetic damage is being inflicted due to long period culture in vitro. To test the possibility regenerated shootlets were subcultured at one month interval over a period of three months on MS with $0.5 \mathrm{mg} / \mathrm{l} \mathrm{BAP}$ and $60 \mathrm{mg} / \mathrm{l}$ ADS. To ascertain the genetic purity at molecular level DNA fingerprinting was performed using ISSR primers. Simultaneously genetic purity of regenerated clones was also examined.

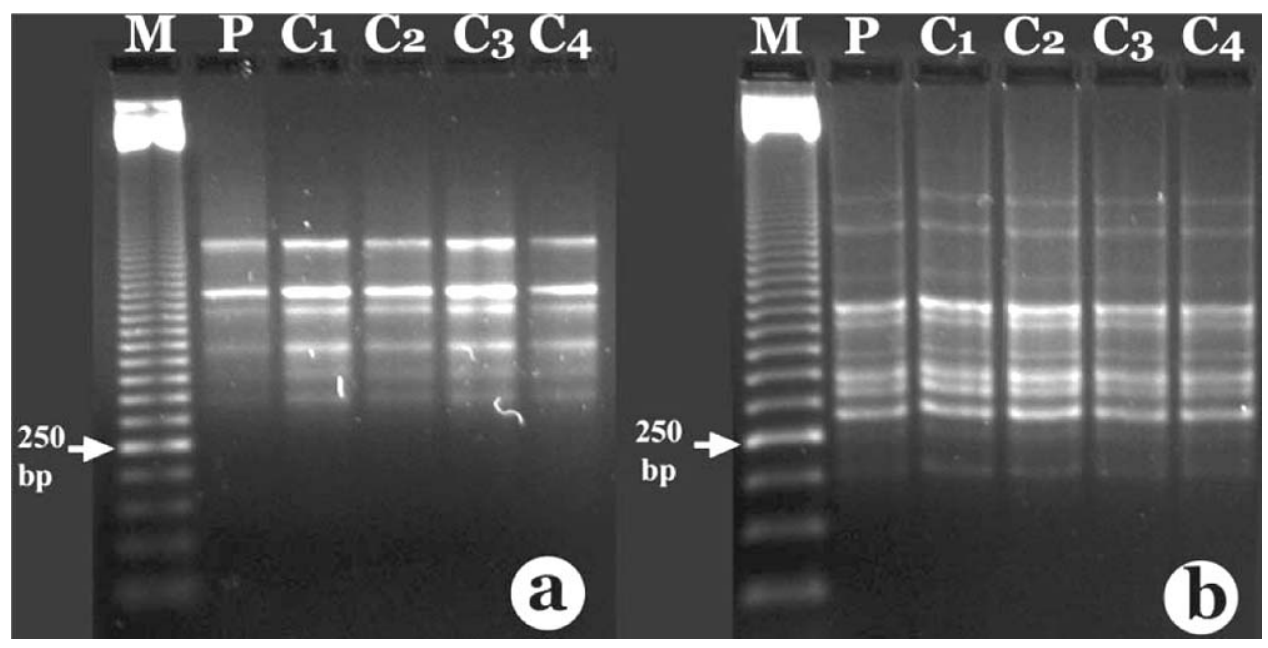

Fig. 2. Agarose gel electrophoresis of ISSR fragments of in vitro regenerated clones $\left(\mathrm{C}_{1}-\mathrm{C}_{4}\right)$ with their mother (P) showing monomorphic bands generated by primer (a) IS-7 (5' GTG TGT GTG TGT GTG TA 3') and (b) IS-61 (5' GA GA GA GA GA GA GA GA T 3'). Lane M - 50bp ladder.

Among 10 ISSR primers used IS-7(5' GTG TGT GTG TGT GTG TA 3'), IS11(5' CAC ACA CAC ACA CAC AG 3') and IS-61(5' GA GA GA GA GA GA GA GA T 3') displayed major reproducible bands. None of the primers showed any difference in banding pattern (Fig. 2a,b) proving that the trueness of the in vitro regenerated clones was maintained. On the other hand, same result was displayed in case of sustained multiple shoot culture also as there was no variation in major reproducible bands among the prolonged cultured clones. This would help maintain sustained activity for tissue culture in anthurium. 
So the present exercise by and large offers a promising approach to engage in commercial activity for ornamental plants like anthurium through tissue culture.

\section{References}

Bhattacharyya S and Mandal RK (1999) Identification of molecular marker in septumless bold pod in Brassica campestris. J. Plant Biochem. and Biotech. 8: 93-99.

Bhojwani SS (1981) A tissue culture method for propagation and low temperature storage of Trifolium repens genotypes. Physiol. Plant 52: 187-190.

Chen FC, Kuehnle AR and Sugii N (1997) Anthurium roots for micropropagation and Agrobacterium tumifaciens-mediated gene transfer. Plant Cell Tissue and Organ Cult. 49(1): 71-74.

Dufour L and Guerin V (2003) Growth, development features and flower production of Anthurium andreanum Lind. in tropical conditions. Scientia Horticult. 98(1): 282-286.

Kunisaki JT (1980) In vitro propagation of anthurium andreanum Lind. Hort.Sci. 15: 508509.

Mahanta S and Paswan L (2001) In vitro propagation of Anthurium from Axillary Buds. Floricult. Today 17(3): 38-40.

Martin KP, Joseph D, Madassery J and Philip VJ (2003) Direct shoot regeneration from lamina explant of two commercial cultivars of Anthurium andreanum Hort. In vitro Cell Dev. Hort. Plant. 500-504.

Nissen SJ and Sutter EG (1990) Stability of IAA and IBA in nutrient medium to several tissue culture procedures. Hort. Sci. 25: 800-802.

Rout GR, Mahapatra A and Jain SM (2006) Tissue culture of ornamental pot plant : A critical review on present scenario and future prospects. Biotechnology Advances 24: 531-560.

Sivanesan I and Jeong BR (2007) Micropropagation and in vitro flowering in Pentanema indicum Ling. Plant Biotechnol. 24: 527-532. 